\title{
Unexplained Male infertility: Diagnosis and Management
}

\author{
Alaa Hamada, Sandro C. Esteves, Mark Nizza, Ashok Agarwal \\ Center for Reproductive Medicine, Glickman Urological and Kidney Institute, Cleveland Clinic (AH, \\ MN, AA) Cleveland, Ohio, USA and Androfert, Center for Male Reproduction (SCE), Campinas, São \\ Paulo, Brazil
}

\section{ABSTRACT}

Unexplained male infertility is a diagnosis reserved for men in whom routine semen analyses results are within normal values and physical as well as endocrine abnormalities were ruled out. In addition to erectile problems and coital factors, immunologic causes and sperm dysfunction may contribute to such condition. New etiologies of unexplained male infertility include low level leukocytospermia and mitochondrial DNA polymerase gene polymorphism. Contemporary andrology may reveal cellular and sub-cellular sperm dysfunctions which may explain subfertility in such cases, thus aiding the clinician to direct the further work-up, diagnosis and counseling of the infertile male. The objective of this article is to highlight the concept of unexplained male infertility and focuses on the diagnosis and treatment of this condition in the era of modern andrology and assisted reproductive techniques. Extensive literature review was performed using the search engines: Pubmed, Science-direct, Ovid and Scopus.

\section{ARTICLE INFO}

\section{Key words:}

Male infertility; Diagnosis,

Semen analysis; Oxidative

stress; DNA damage;

Reproductive Techniques,

Assisted

Int Braz J Urol. 2012; 38: 576-94

Submitted for publication:

March 02, 2012

Accepted after revision:

June 11, 2012

\section{INTRODUCTION}

Infertility remains both prevalent and problematic among couples worldwide. It is clinically defined as failure of a couple to conceive after one year of regular sexual intercourse. An estimated $4-17 \%$ of couples seek medical treatment in order to rectify their infertility, and it is reasonable to assume that there are many more cases of infertility that are unreported (1). It has been shown that the male factor is solely and partially implicated in 20-50\% of the cases of infertility (2). However, despite advances in technologies and diagnostic methods in the field of andrology, there remains a significant subset of these subfertile men who are classified as having unexplained male infertility (UMI). Men are categorized as having UMI when they are infertile despite having normal semen analysis, normal history and physical examination and when female factor infertility has been ruled out (3). The average incidence of UMI is approximately $15 \%$, although reports of UMI in study populations have ranged from 6\% to 37\% (4-6). Possible factors that might explain the difficulties to conceive in UMI include the presence of antisperm antibodies, sperm DNA damage, elevated levels of reactive oxygen species (ROS), and sperm dysfunction. A further possibility to consider is unexplained female factor infertility and coital factors such as inappropriate timing of intercourse (not within the female fertile window), erectile dysfunction or anejaculation. It is therefore important that both a thorough initial assessment 
is performed, including a detailed sexual history and gynecological examination, as well as advanced investigations that test for autoimmune infertility and sperm defects. The objective of this article is to highlight the concept of unexplained male infertility and focus on the diagnosis and treatment of this condition in the era of modern andrology and assisted reproductive techniques.

The importance and limitations of routine semen analysis in unexplained infertility

Currently, routine semen analysis remains the backbone of the evaluation of the male factor infertility, besides detailed medical history and thorough physical examination (7). Such practice is based on the fact that the semen parameters such as sperm concentration, motility, and morphology have been shown to be significantly related to conception. In addition, being a costeffective and non-invasive test has lead to the widespread use of semen analysis in the initial evaluation of infertile men (8). Nonetheless, the criteria for normal semen parameters vary according to which edition of the WHO laboratory manual for the examination and processing of human semen is used (9).

In 2010, the World Health Organization (WHO) has established new reference values for human semen characteristics which are markedly lower than those previously reported (10). Approximately 2,000 men from eight countries whose partners had a time-to-pregnancy of $\leq 12$ months were chosen as individuals to provide reference distributions for semen parameters. Despite using controlled studies involving couples with known time to pregnancy to establish the new limits, reference studies were limited with regard to the population analyzed and the methods used for semen evaluation. The utilization of the new WHO manual reference values into clinical practice will likely result in a re-classification of many of the infertile couples. Specifically, those couples previously classified as having male-factor infertility with sperm parameters above the new reference limits but below the old values will now be diagnosed as having unexplained or female-factor infertility (9). It is unclear at this time, whether this re-classification will result in a more cost-effective evaluation of the infertile couple or in a delay in the male factor evaluation with subsequent delay in the definitive diagnosis and management of the infertile couple.

The 95\% reference interval for semen characteristics of recent fathers, included in the newest WHO manual, have been generated in line with clinical chemistry standards and the 5th centile was proposed for the lower limit of semen characteristics. Although reference values are useful for comparison with values obtained from the patient being assessed, it is important not only to compare the patient results with the lower reference limit but also with the 50th percentile, which represents the value beneath which $50 \%$ of the reference population of 'fertile' men falls. This strategy may be more realistic and can help in understanding a patient's seminal profile in relation to a given reference group (9).

It is therefore important to acknowledge the limitations of semen analysis results in predicting the health and functional capacity of the male reproductive organs and cells. Normal semen analysis does not guarantee the fertilization potential of sperm, and studies have shown significant overlap in semen parameter values between fertile and infertile men (11). This overlap could be due in part to the marked biological variability in semen samples characteristics, even those taken only a few days apart from the same individual (2). Furthermore, semen analysis does not provide information regarding defects in sperm function. Many key aspects of the fertilization process such as transport of the sperm to the oocyte, sperm interaction with the cervical mucus, and sperm interaction with the oocyte cannot be assessed by conventional semen analysis. For this reason, it has been suggested that sperm function tests should be included in the semen analysis of individuals seeking fertility evaluation (3). Lastly, the male evaluation regarding fertility must go far beyond counting spermatozoa and assessing motility and morphology. It has to be complemented with a proper clinical examination, a comprehensive history taking, and relevant endocrine, genetic, and/or other investigations.

Thus, it is imperative to conclude that further tests are certainly required beyond se- 
men analysis for evaluating subfertile men. The time has come for technological developments in the field of andrology to bring robust and costeffective clinically useful sperm function tests to fix the shortcomings of the routine semen analysis. The term omics encompass the study of genes (genomics), transcript (transcriptomics), proteins (proteomics) and metabolites (metabolomics) (12). These technologies allow for the identification and quantification of cellular components in a spatiotemporal fashion. What researchers once envisioned is now a reality; omics now allows for a transformation from once only genomic analysis to proteomic analysis. This approach offers an opportunity to investigate the relationship between an organism's genotype and resulting phenotype. Sperm proteomics, for instance, is the identification and functional study of sperm proteins. It is based on the separation of proteins to generate a sample suitable for mass spectrometry and subsequent protein identification. Currently it has led to the identification and cataloging of thousands of sperm proteins. Ultimately, the goal is to apply sperm proteomics not only as a research method, but also as a clinical and diagnostic tool in the field of male infertility. The spermatozoon is an excellent target for proteomics because the functional transformation of these cells during their journey from the seminiferous tubules to the surface of the oocyte takes place in the complete absence of contemporaneous gene transcription (12). Development and clinical application of novel sperm function tests, including the 'omics' technology, may improve precision and reliability to the diagnosis of male subfertility (13).

\section{Clinical evaluation of the subfertile male}

It is important that the initial assessment of subfertile male patients is rigorous and detailed in order to rule out any evident cause of infertility before delving deeper into evaluating the potential etiologies of unexplained male infertility. The initial workup should furst include an exhaustive recording of the patient's medical history and physical examination. For men with normal semen analysis particular emphasis should be applied upon history of previous fertility, duration of infertility, history of frequent miscarriages, congenital abnormalities in the previous pregnancies and medications. Detailed coital history from both partners discloses several problems such as erectile dysfunction, anejaculation, inappropriate coital technique, infrequent intercourse and inappropriate timing of the intercourse $(7,14,15)$.

Next, a physical examination of the patient should be performed to rule out other potential sources of infertility. Again for infertile men with normal semen analyses, attention should be paid towards penile abnormalities such as a hypospadiac urethral meatus or severe chordee which may lead to deposition of sperm into the vaginal cavity at an insufficient proximity to the cervix. The testes and epididymis and spermatic cord should be carefully palpated in order to rule out the presence of potential sources of oxidative stress culminating in sperm dysfunction such as epididymitis, epididymo-orchitis, and varicocele $(16,17)$.

Following medical history and physical examination, semen analysis is the first laboratory test that will be run in the initial workup. Seminal fluid collected from the patient following 2-5 days of abstinence should be assessed with regard to volume, sperm concentration, motility, and morphology in comparison to WHO defined cutoff values for fertile men. At least two samples should be analyzed although the ideal interval between analyzes has not been defined yet. Although fertilization potential decreases as semen parameters decrease in quality, it is difficult to designate patients as fertile or subfertile based on semen analysis alone (2). However, semen analysis in conjunction with previous evaluations in the initial workup may contribute to the diagnosis of infertility or prognosis of fertility potential (18).

An endocrine evaluation in infertile men with normal semen parameters can hardly be of any significance (19). A thorough evaluation of the female partner by gynecologist should also take place in order to rule out implication of the female factor in the unexplained couple's infertility.

\section{Etiologies}

Immune infertility

Spermatogenesis does not occur until the onset of puberty and sperm are kept separated 
from the immune system by the blood-testis barrier. When the blood-testis barrier is breached for any reason and sperm antigens come into contact with the immune system they will be treated as foreign agents resulting in antisperm antibody (ASA) formation (20).

While previous trauma, infection and obstruction have been implicated as clear etiologies for ASA formation, many cases of immune infertility have not had these events (20-22). Antisperm antibody formation has been reported in $42 \%$ of men with unexplained infertility, 10.7\% of men undergoing infertility evaluations, 10\% of men in couples undergoing IVF treatment but only in 2\% of fertile men (23-26).

Immunoglobulin classes A (IgA) and $\mathrm{G}$ (IgG) are the functionally significant antibodies with respect to male infertility as IgM have high molecular weight and cannot penetrate the blood testis barrier. These antibodies bind to the sperm and reduce fertilization capability. Clark et al., demonstrated a $27 \%$ fertilization rate when $\geq$ $80 \%$ of sperm contained sperm-bound IgA and IgG, while fertilization rate of $72 \%$ was seen when $\leq 80 \%$ of sperm had sperm-bound ASA (27). It is not clear whether the location of the sperm-bound, whether sperm head or tail, ASA is significant, as there are conflicting reports assessing the value of localization and its relation to fertilization capacity (28).

ASA have the capability to disrupt several phases of the multi-step fertilization process. Complement in female cervical mucus can bind to antibodies and cause lysis of the sperm cell, reducing motility and inhibiting the ability of sperm to penetrate cervical mucus (28-30). Evidence suggests ASA cause sperm to have lower rates of spontaneous and induced acrosome reaction compared to sperm in ASA absent serum $(31,32)$. Certain ASA have also been shown to inhibit spontaneous sperm capacitation reaction, and there is evidence to suggest that ASA can interfere with recognition of sperm binding sites on the zona pellucida (28).

Sperm agglutination or clumping is the only well-known semen abnormality that is correlated with the presence of ASA. Such phenomenon is time-dependent and only rarely involves a large proportion of motile spermatozoa soon after liquefaction even when all ejaculated spermatozoa are antibody coated $(33,34)$. Moreover, semen contains several substances that inhibit the activation seminal complement system which is required by the immobilizing and apoptogenic ASA $(35,36)$. Therefore, finding of normal semen parameters in men with immune infertility is a common event.

\section{Reactive oxygen species}

Reactive oxygen species (ROS) are unstable oxygen derived molecules that are formed as byproducts of oxidative metabolism. These metabolites include free radicals and non-free radical molecules. Hydroxyl ions and superoxide are examples of free radicals, whereas hydrogen peroxide and lipid peroxide are examples of nonradical species [36]. Reactive nitrogen species are also included in the ROS category; some examples include nitrous oxide, nitroxyl ion, and peroxynitrite $(37,38)$.

In human semen, the primary producers of ROS are leukocytes and immature spermatozoa (39). In spermatozoa ROS are generated through two ways: NADPH oxidase system at the level of the sperm plasma membrane and the NADH-dependent oxido-reductase system at the mitochondrial level (40). Conditions that provoke inflammatory cells accumulation in the genital tract such as infections or lead to production of immature sperm such as varicocele, lifestyle factors that stimulate sperm to generate excess of ROS such as smoking are all implicated $(17,41,43)$.

Polymorphonuclear leukocytes and macrophages represent approximately 50-60\% and $20-30 \%$ of all seminal leukocytes, respectively (44). These leukocytes can be activated by infection and inflammation, in which case they are capable of producing 100 times greater amounts of ROS than inactivated leukocytes $(45,46)$. In addition, even low level leukocytospermia (below 1 million of white blood cells per 1 milliliter of semen) has been recently discovered to be harmful, and therapy of such low levels of leukocytes may result in improvement in pregnancy rates $(43,47)$.

There is strong evidence that smoking is linked to increase in ROS. Many of the 4,000 com- 
pounds in tobacco smoke are either reactive oxygen or nitrogen species. A study of smoking and non-smoking infertile men showed a 48\% greater seminal leukocyte concentration and a 107\% increase in ROS levels among smokers $(41,42)$. Alcohol abuse and exposure to radiation and toxic chemicals can also increase seminal ROS (48).

ROS are physiologically essential in the fertilization process by aiding in sperm acrosome reaction, hyperactivation, motility and capacitation (49). However, greatly elevated levels of ROS can overwhelm the body's natural anti-oxidant defense and cause damage, a condition known as oxidative stress (OS). Studies have shown that elevated ROS levels can be found in 40-80\% of infertile men (50). Additionally, elevated ROS levels can be found in up to $11-78.5 \%$ of infertile patients with normal semen parameters (51-53). Lipids such as the polyunsaturated fatty acids present in the sperm plasma membrane are the most chemically susceptible macromolecule to OS (54). Damage to the plasma membrane leads to impaired sperm function such as a decrease in motility and failure to undergo sperm-oocyte fusion $(55,56)$.

\section{Genetic defects}

Genetic damage in sperm can occur at several levels, all of which have the potential to cause infertility in men. Sperm chromosomal abnormalities are most often seen in men with decreased sperm cell count (oligozoospermia), decreased motility (asthenozoospermia), or high percentage of morphologically abnormal sperm (teratozoospermia) (57). Several reports have shown the rates of disomy for autosomes and sex chromosomes are $0.11 \%$ and $0.44 \%$ for normozoospermic infertile men, and the rate of diploidy is $0.3-1 \%(58,59)$. The likelihood of sex chromosomal abnormalities are 15 times greater in infertile men than in the general population, while autosomal abnormalities occur with six times greater frequency $(60,61)$.

Gene mutations and polymorphism have been also recognized in infertile men with normal spermiograms. CatSper gene 1 mutation, which will be described later under hyperactivation defects, and CAG repeat polymorphism in the gene coding for polymerase gamma (POLG) are examples for such gene abnormalities. Polymerase gamma is the catalytic subunit of the enzyme mitochondrial DNA polymerase that is responsible for synthesis and repair of mitochondrial DNA. Mitochondrial DNA encodes several mitochondrial proteins that are important in generation of energy and ROS. PLOG gene polymorphism is discovered in infertile men with normal spermiogram. The sperm from these men have lower oocyte penetration ability and fertilization rates (62).

Recently, Garrido et al. conducted microarray analysis on sperm mRNAs in sperm samples of normospermic infertile men versus fertile controls and showed differential expression of hundreds of genes between the two study groups (63). Moreover, when determining genes that are ten times or more differentially expressed, three genes are overexpressed, whereas 136 genes are underexpressed in infertile normospermic men vs. fertile controls. This study provides clear evidence of genetic contribution to UMI, however, analytic functional data of these differentially expressed genes and their products are incompletely understood and further studies are certainly needed to examine their roles.

Sperm DNA damage is a broad term that accounts for many defects in the DNA structure including: single or double DNA strand breaks, base deletion or modification, inter-strand or intra-strand cross-linkage, and DNA-protein crosslinkage (64). Post-meiotically initiated abortive apoptosis, unresolved strand breaks during spermiogenesis, and oxidative stress have all been implicated as potential sources of this damage (65). Additional factors associated with altered DNA integrity include advanced paternal age, inadequate diet, drug abuse, tobacco use, environmental factors such as pesticide exposure or air pollution, varicocele, systemic diseases, and genital inflammation (66). Studies have linked DNA damage with infertility, showing greater DNA damage in the sperm of infertile men than of fertile men $(67,68)$. In fact, it has been suggested that sperm DNA fragmentation is one of the chief causes of reduced fertility potential. DNA damage is reported in 5-8\% of infertile normozoospermic men $(66,69)$. In a recent controlled study on small 
number of infertile normozoospermic individuals ( $\mathrm{n}=28$ ), sperm DNA integrity defects measured by sperm chromatin structure assay was reported to be 89.2\% (53).

High percentages of DNA damage in spermatozoa have a negative impact on a man's ability to achieve pregnancy naturally, and are correlated with spontaneous pregnancy loss $(70,71)$. It has also been shown that high rates of DNA damage in spermatozoa are correlated to failure of fertilization in intrauterine insemination (IUI) (72) and conventional in vitro fertilization IVF (72-74) but not with ICSI $(72,74,75)$. Although sperm DNA integrity emerges as a specific marker of male fertility potential, clinical utility of such test may be undermined by lack of consensus on a standardized method of measurement and universal cut off value.

\section{Fertilization defects}

Fertilization of the oocyte involves multiple complex and intricate processes. Defects in any one of these processes can hinder the sperm fusion with the oocyte and formation of the zygote. One of the first steps of fertilization is capacitation. Sperm capacitation occurs naturally during travel through the female reproductive tract, while in vitro capacitation can be induced by removal of seminal plasma and subsequent addition of corresponding culture medium (76). Several changes are observed in the sperm that undergo capacitation, including changes in membrane composition, membrane potential, intracellular $\mathrm{pH}$ and calcium levels, and changes in the protein phosphorylation (57). Hortas et al. (77) examined in particular the activity of sperm protein phosphorylation in relation to capacitation. The study observed low expression of D-mannose receptors in 6 of 15 subjects with unexplained infertility, revealing a failure of normal physiological capacitation development. These various alterations are induced by efflux of cholesterol as well as shifts in ion channel and transport activities (78). Capacitation increases the capacity of the sperm to fuse with the oocyte membrane and prepares the cell to undergo hyperactivation as well as acrosome reaction (79).

Sperm ability to undergo proper hyperactivation (HA) has been shown to relate to its fer- tilization potential (80). The sperm motion pattern changes from progressive to motility characterized by lateral head displacement, high curvilinear velocity and large amplitudal flagellar waves (81). This style of motility is termed 'hyperactivation motility' and essential in the fertilization process, as it allows the sperm to travel through the cervical mucus and cumulus oophorus and penetrate the dense zona-pellucida (11). Mackenna et al. (82) observed that the ability of follicular fluid to induce sperm hyperactivation was significantly lower in men with unexplained infertility compared to fertile men.

The exact physiological mechanism for hyperactivation is thought to be an increased intracellular calcium entry through sperm calcium channels known as CatSper1-4 (83-85). CatSper1-4 is located in the sperm principle piece, along with various other voltage gated proton pumps important to the initiation of hyperactivation (83). Avenarius et al. discovered that male patients with mutated CatSper1gene are infertile with poor HA response despite their normal sperm count, morphology and even their initial motility (86). Interestingly, there are two known CatSper2 gene related mutations in humans that cause male infertility, termed CatSper-related non-syndromic male infertility and deafness-infertility syndrome (87). However, both syndromes are associated with gross semen abnormalities. Further investigation is needed to disclose the genetic and molecular nature of fertilization in patients with defective HA response and unexplained infertility. Moreover, minor mutations in human CatSper genes are yet to be deciphered in males with unexplained infertility.

Sperm binding to the zona pellucida is essential in the process of fertilization and is an important precursor to the acrosome reaction. There are specific receptor-ligand interaction between the sperm cell and the zona glycoprotein layer of the oocyte that allows for mutual recognition and subsequent binding (57). The ZP3 protein on the oocyte is the chief protein involved in sperm zona pellucida binding (88). The exact identity of the ZP3 receptor on the sperm has not yet been identified, although studies have concluded the most likely candidate is beta-1, 4-galactosyltransferase 
I (GaIT) $(88,89)$. During ovulation the zona pellucida is surrounded by cumulus oophorus consisting of cumulus cells embedded in an extracellular matrix primarily composed of hyaluronic acid. The protein sperm adhesion molecule 1 (SPAM1) is sperm plasma membrane molecule which is capable of hyaluronidase activity to traverse through the cumulus oophorus and bind to the zona pellucida (90). Defects in ZP binding are reported in $15 \%$ of infertile men with normal semen (91-93).

Sperm binding to the zona pellucida triggers the release of hydrolyzing enzymes known as the acrosome reaction (AR). AR is essential for fertilization both because it allows the sperm cell to penetrate the zona pellucida and exposes the site of the sperm that fuses with the oocyte plasma membrane (57). Acrosin is the specific enzyme that is released. Physiological inducers of the AR are the protein ZP3 and progesterone, which is found in high concentrations in follicular fluid and cu- mulus (94-96). These compounds are agonists which stimulate intracellular calcium concentration, producing a shift of internal $\mathrm{pH}$ and stimulating the exocytotic process (94). The timing of $A R$ is very important, as sperm that undergo AR prior coming in contact with the $\mathrm{ZP}$ binding are unable to either bind to or penetrate the ZP (91). One study showed that defective zona pellucida induced-acrosomal reaction (ZPIAR) was found in $25 \%$ of normozoospermic subfertile men (97).

\section{Management}

A proposed algorithm for the clinical management of men with UMI is depicted in Figure-1.

\section{Expectant management}

Once thorough initial assessment is conducted and immediately treatable causes of infertility, as well as presence of a female factor have been ruled out, the clinician then must de-

Figure 1 - A proposed algorithm for the clinical management of men with unexplained male infertility.

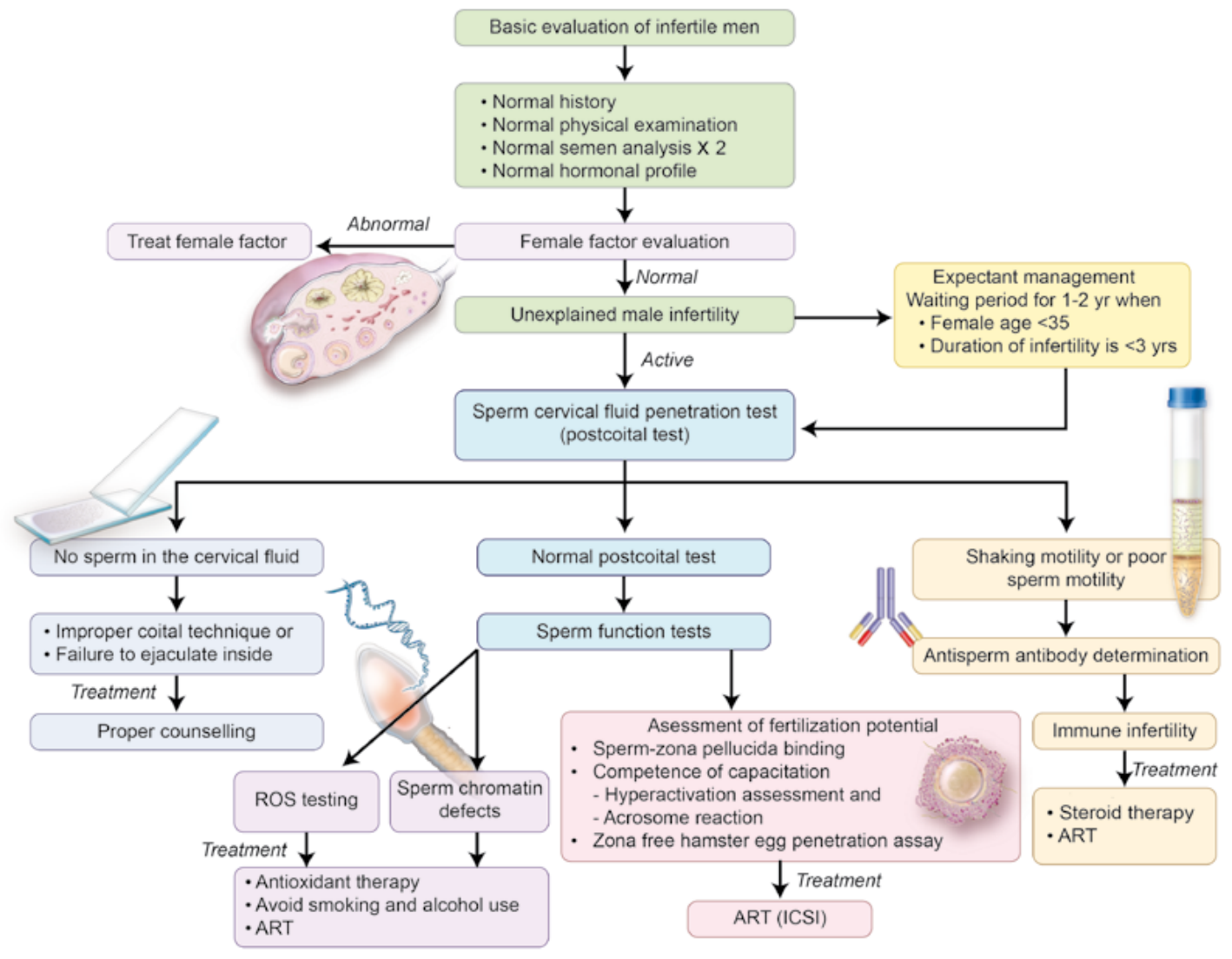


cide how to proceed in managing men with unexplained infertility. It should be kept in mind that the reported chance of conception per cycle of a sexually active so-called 'fertile' couple is 15$20 \%$ and the cumulative chance of pregnancy is approximately 85\% per year (98-100). Therefore, that leaves $15-20 \%$ of couples who would be defined as having infertility and only a subset of those will fit in the unexplained category. Studies have shown that spontaneous conception occurs in the majority of couples with unexplained infertility in the next 1-2 years if they continue to have fertility-focused intercourse $(101,102)$. One study reported that over $50 \%$ of such couples will have a live birth within 36 months after failing to achieve pregnancy in the first year (102). A landmark study by Hull et al. found a cumulative pregnancy rate of 50-80\% over three years as a function of female age, and $30-80 \%$ as a function of infertility duration (100). Other studies report spontaneous pregnancy rate of $60 \%$ within 2 years of being classified as infertile (103). However, as Hull et al. report showed, these rates can vary with female age and duration of infertility. Female partner age greater than 35 or infertility duration of more than 3 years are associated with a significant decrease in spontaneous pregnancy rate. After more than 3 years of infertility, the chance of spontaneous pregnancy drops $2 \% \mathrm{ev}-$ ery year after the age of 25 . Additionally, monthly fecundity rates in couples with unexplained infertility and female partner age over 35 are only $1-3 \%(100,103,104)$.

These results lead to several conclusions in determining how the clinician should proceed with the management of men with unexplained infertility. Young couples with short-term infertility and female partner age under 35, particularly under 30, may be withheld from treatment and expectantly followed, as the spontaneous pregnancy rate in these couples is very high. This is combined with the fact that advanced investigations and treatment are costly, and that natural means of conception is most desirable amongst these couples. On the other hand, couples with infertility lasting more than 3 years or with female age greater than 35 should be immediately referred to an active management plan that in- cludes advanced investigations and possible ART treatment options.

\section{Interventional management}

Once a clinician deems active intervention for a couple with unexplained male infertility, he or she is then faced with the prospect of identifying the precise cause of infertility. This is a crucial step, as it allows the most appropriate treatment option to then be considered. A multitude of tests are available which can assess the various potential defects causing infertility. Many of the tests are extremely specific, examining only one aspect of the multi-step fertilization process. Therefore, in the interest of the cost and time, as well as overall benefit to the patient, it is necessary to first narrow down the potential causes of the man's unexplained infertility. The post-coital test (PCT), when is appropriately performed, can be a valid initial indicator of what aspect of fertilization should be first evaluated and treated.

The PCT provides an assessment of the quantity and quality of cervical mucus, spermmucus interactions and the presence of antisperm antibodies $(101,102)$. The test involves microscopic examination of extracted endocervical mucus, which should be conducted in the pre-ovulatory phase and 8-12 $\mathrm{h}$ after intercourse. However, controversy remains surrounding the predictive power of the PCT for conception $(101,102)$. Glazener et al. (105) determined that, although the PCT test is a poor predictor of pregnancy in couples with unexplained fertility for duration of greater than 3 years, it is nonetheless a good initial assessment of sperm function, provided that care is taken to eliminate negative results caused by poor mucus quality. First, the PCT test must be performed near the time of ovulation, otherwise the cervical mucus is hostile to sperm and an abnormal result will occur. Second, adequate waiting period (8-12 hours) should be given for PCT before reading the results. The reason is that detection of certain abnormalities such as ASA requires this period for activation of complement system in the cervical mucus to exert their effects on sperm. A properly timed PCT test can present one of three results: 1) no sperm is present in the cervical fluid, 2) the PCT test is normal or 3) adequate number 
of sperm are seen but of poor motility or shaking motion (Figure-1). In cases where no sperm are observed in the cervical fluid particular emphasis should be applied on improper coital techniques, abnormal penile curvature or anejaculation while poor sperm motility or shaking is suggestive of the presence of ASA. It should be noted, however, that results of the PCT are subject to considerable intra- and interobserver variability (106). Unfortunately, routine use of this test in clinical practice has led to the widespread use of ART for couples with a negative PCT. It is important to stress that a negative PCT result is not suitable to indicate a treatment modality, and the use and interpretation of this test should be well balanced (107).

Subsequently, more specific tests should be performed by the clinician in order to confirm that ASA are present in significant quantities and these ASA are interfering with sperm function. The most effective test available for detecting the presence of ASA is the direct immunobead test (IBT) (Figure-2). The World Health Organization considers the patient with ASA positive if greater than $50 \%$ of sperm are ASA bound (108). Direct mixed antiglobulin reaction (MAR) tests are very similar to the IBT. The Sperm MAR test, for example, uses latex particles, instead of immunobeads, that are coated with antihuman IgG.

Several approaches are used to treat ASA as a cause of male infertility such as steroid therapy and assisted reproductive techniques. Corticosteroid treatment suppresses the immune system, and thereby decreases ASA production. The effectiveness of this treatment is otherwise questionable. One study showed that of infertile men with ASA treated with steroids for 3 cycles, only $20 \%$ showed a decrease in sperm-bound ASA (109). Another study showed the steroids had little effect of steroids on sperm-bound IgA in infertile men, and furthermore revealed no significant difference in pregnancy outcomes between the treated group and a placebo group (110). This lack of definitive benefits of corticosteroids, coupled with the risks that steroid use has on human body such as Cushing's syndrome, bone osteonecrosis, fluid and electrolyte imbalance discourage clinicians from use of this modality of treatment. Another possible treatment option for managing
Figure 2 - Immunobead test. Spermatozoa are mixed with beads that have been coated with IgG class-specific secondary antibodies. Reprinted from Int J Urol. 2010; 17: 839-47. Samplaski, et al. New generation of diagnostic tests for infertility: review of specialized semen tests, with permission from publisher (John Wiley and Sons) (127).



patients with ASA is to use assisted reproductive techniques such as intrauterine insemination (IUI) and in vitro fertilization (IVF). Prior removal of ASAs that are already bound to the sperm by methods such as sperm washing and IgA protease treatment, yields limited success in several studies. Agarwal et al. (111) found that among 45 couples who underwent IUI and sperm washing treatment for two years, 15 couples achieved pregnancy. Kutteh et al. (112) used IgA protease treatment and reported an $80 \%$ decrease in ASA bound to the sperm but the author did not show the advantages of such finding on improvement of sperm function and fertilizing potential. The most successful method of treatment for male patients with ASA is intracytoplasmic sperm injec- 
tion (ICSI) as it bypasses the otherwise necessary fertilization mechanisms that can potentially be affected by ASA. One study showed that couples who had a poor fertilization rate during IVF (6\%) showed a dramatic increase in fertilization rate with ICSI treatment (79\%) which was comparable to an ASA negative group (68\%) (113). In another study, Esteves et al. reported that the outcome of ICSI in men with autoimmune infertility was not influenced by the percentage of ASA-bound spermatozoa (114).

Normal PCT results can direct further work-up towards unraveling other potential causes of unexplained male infertility cases such as oxidative stress, DNA damage and fertilization defects.

\section{Oxidative Stress}

Currently, the most common way to measure ROS is by chemiluminescence assay which indirectly measures seminal ROS levels. It records the intensity of light produced from the reaction of the luminol probe with the ROS in relative light units (RLU). Chemiluminescence measures both intra and extracellular ROS. To ensure accurate readings, semen samples should contain sperm concentration $1 \times 106 / \mathrm{mL}$ or greater and be analyzed within the first hour of collection. Flow cytometry can also be used to measure intracellular sperm ROS; however this is a much more expensive tool and thus is not as practical for widespread clinical use.

There are several treatment possibilities for excess ROS. The patient should be immediately advised to avoid tobacco use as abstinence from tobacco use could help lower seminal ROS levels (42). Lifestyle modifications such as losing weight for obese men, eating of fruits and vegetables are also helpful. Moreover, recent reports support the use of antioxidants for treatment of oxidative stress related male infertility. Antioxidants serve to prevent excessive ROS formation and subsequent damage by interrupting free radical chain reactions and forming non-harmful non-radical end product. Some clinical trials were able to demonstrate beneficial effects of antioxidant therapy in cases of male fertility in terms of improving semen parameters, pregnancy rates and sperm DNA fragmentation index (measure for DNA integrity defects) (115). Useful antioxidants include vitamin E, Vitamin C, Coenzyme Q-10, selenium, zinc, lycopene and carnitine. A recent Cochrane meta-analysis on the use of oral antioxidants in male infertility found that these agents significantly improved pregnancy rates and live births and decreased sperm DNA damage (116). The evidence suggests that antioxidant supplementation in subfertile males may improve the outcomes of live birth and pregnancy rate for subfertile couples undergoing fertility treatment. However, large clinical trials are still necessary to identify the superiority of one antioxidant over the other in different subpopulations of infertile males, as well as other important aspects such as dose and duration of therapy. Lastly, Hamada et al. reported that even low level leukocytospermia (important source of ROS) may be harmful and prescribing doxycycline $200 \mathrm{mg}$ twice daily for three weeks results in significant improvement in pregnancy rates (47).

\section{Chromosomal abnormalities and DNA damage}

Several methods exist for the detection and evaluation of sperm chromosomal and DNA abnormalities such as sperm Karyotype and fluorescence in situ hybridization (FISH). FISH is not only very highly sensitive and specific method, but it also allows for the study of much greater numbers of spermatozoa, therefore increasing both the accuracy and efficiency of the process of detecting sperm chromosomal aneuploidy rates in infertile men. It should be noted however that sperm chromosomal abnormalities are exceedingly rare in patients with UMI.

On the other hand, assessment of sperm DNA integrity has greater importance for about $10 \%$ of men with normal semen analysis. These men may harbor single or double-stranded DNA fragmentation $(66,69)$. Various tests exist that allow for detection and evaluation of sperm DNA damage in spermatozoa. These tests can be categorized as either direct or indirect measurements of DNA damage. Comet assay, also known as single cell gel electrophoresis, is a sensitive technique that measures DNA damage directly. Terminal deoxy-nucleotidyl transferase-mediated 
deoxyuridine triphosphate (dUTP) nick end-labeling (TUNEL) assay is another sensitive and specific method for measuring of sperm DNA damage. Unlike Comet, TUNEL is able to detect both single and double strand breaks simultaneously (117). However, TUNEL only reveals the number of cells with DNA damage in a population, while Comet is able to quantify the degree of DNA damage in each cell (118). The sperm chromatin structure assay (SCSA) is an indirect method of assessing DNA damage by measuring sperm chromatin integrity. In SCSA, sperm DNA is exposed to acridine orange which binds to DNA (67). This acridine orange fluoresces green when it is attached to normal double stranded DNA, and red when bound to single stranded fragmented DNA. The ratio of green to red fluorescence is determined in what is known as the DNA fragmentation index (DFI). The advantages of SCSA are that it is relatively simple and quick procedure and the DFI has been identified as a useful predictor of pregnancy (118).

There is some debate, however, regarding what the cut off values should be in categorizing men as fertile or infertile based on DNA damage, as well as what tests should be used. Chohan et al. (119) observed that results of various tests correlated well with each other. DFI as measured by SCSA seems to currently be the most established indicator of DNA damage. Several studies report a cut off value greater than 30\% in DFI has shown to be associated with significant decreases in IVF fertilization as well as clinical pregnancy rates, with dramatically higher rates of success below the cut off $(72,120,121)$. Esteves et al. (7) asserted that TUNEL was the best method for observing DNA fragmentation rates, citing the test's ability to precisely identify all existing breaks in sperm DNA. Cut off values for TUNEL are a subject of debate among researchers. One study demonstrated that when greater than $12 \%$ of DNA was fragmented, as assessed by TUNEL, IUI success rates were $0 \%$ (122). Another study claimed a cutoff rate of $19.25 \%$ DNA fragmentation differentiated fertile from infertile men (123). The desire to define established cut off values for TUNEL stems from the fact that it is less technically demanding than SCSA, and can provide more specific information as well (123).
ICSI is the primary treatment option for patients with a rate of DNA damage above the established cut off value for the corresponding test $(124,125)$. Fragmentation of spermatozoal DNA is linked with defects in various fertilization processes, and thus fertility is restricted by natural barriers in IVF and IUI treatments. ICSI, however, bypasses those natural barriers, allowing for direct fertilization of the oocyte. The data seems to support this theory, as studies have found no correlation between high rate of DNA damage and fertilization rate in ICSI treatment $(72,74,126)$. Patients should be advised, however, that the effects of spermatozoa with DNA damage being used for fertilization are still controversial, and further testing is required to assess potential long term effects.

\section{Fertilization defects}

Sperm function tests for fertilization potential are particularly useful in discovering the cause of a man's otherwise unexplained infertility, and it has often been found that the infertile male patient yields poor functional test results in the face of otherwise normal semen analysis parameters. The sperm penetration assay (SPA), also known as the zona-free hamster oocyte penetration assay is one of the common tests used to measure a spermatozoa's ability to undergo capacitation, AR, fusion and penetration through the oocyte plasma membrane, and finally decondensation within the cytoplasm of the oocyte (127). The SPA uses hamster oocytes whose $\mathrm{ZP}$ has been removed to allow for cross species fertilization. The human sperm is incubated with the zona-free hamster oocytes and the percentage of ova penetrated, as well as the number of sperm penetrations per ovum are measured (8). Normal values for fertile men are $10-30 \%$ ova penetrated (8). One study revealed that $34.1 \%$ of patients with UMI scored less than $10 \%$ ova penetrated (128). The SPA is highly sensitive as it has been shown to be positively correlated with IVF fertilization rates as well as achievement of pregnancy in patients with UMI, and practical, as it uses readily available hamster oocytes rather than human ones $(69,129,130)$.

There are several additional tests which assess specific defects in fertilization processes. 
Sperm-ZP binding and AR are two particularly important functions that can be examined. The hemizona assay evaluates sperm ability to bind to the ZP. Zona pellucida from a human oocyte is isolated and divided in half. One half is incubated with sperm from a fertile donor, while the other half is incubated with the patient's sperm. The number of sperm bound to the $\mathrm{ZP}$ in each group is counted following incubation, and a ratio of patient to fertile is calculated (Figure-3). A ratio of less than $30 \%$ is considered abnormal, and the patient would be determined to possess a defect in sperm ability to bind to the ZP. Poor ZP binding rates are associated with high rates of IVF failure (131). The availability of human oocytes is limited, and thus this test should only be performed if multiple failed IVF attempts have occurred (132).

Once the sperm has bound to the ZP, AR must occur in order to penetrate the zona pellucida and fertilize the oocyte. Tests exist that can independently assess both the integrity of the acrosomal cap as well as the functional ability of the sperm to release the acrosomal enzymes. Fluorescently labeled plant lectins such as pisum sativum agglutinin (PSA) binds to chemicals in the acrosomal matrix. However, PSA cannot penetrate intact acrosomal membranes, and thus can only identify acrosome reacted sperm. Conversely, peanut agglutinin (PNA) binds to outer acrosomal membranes and thus can indicate sperm cell which remains acrosome-intact. These lectin tests do not differentiate between acrosome reacted sperm and morphologically abnormal sperm with damage to the plasma membrane, therefore cell viability assessment and removal of damaged sperm should be conducted to ensure accurate results (133). The competence of acrosomal enzymatic release in sperm can be directly assessed. Sperm can be prompted to undergo AR in the presence of an artificial inducing agent, ionophore A23187, or natural physiological inducers, progesterone or ZP3 $(57,127)$ (Figure-4). The percent of reacted sperm can be counted, and studies show that semen samples containing 5-30\% reacted sperm have higher fertility potential (134). Again, these are very specialized tests, and are recommended only in the event of multiple IVF failure (57).
Figure 3 - Hemizona assay. The zona pellucida is isolated and divided in half. One half is incubated with fertile donor sperm (positive control) and the other half is incubated with patient sperm. The ratio of fertile to donor binding is measured. Reprinted from Int J Urol. 2010; 17: 839-47. Samplaski, et al. New generation of diagnostic tests for infertility: review of specialized semen tests, with permission from publisher (John Wiley and Sons) (127).

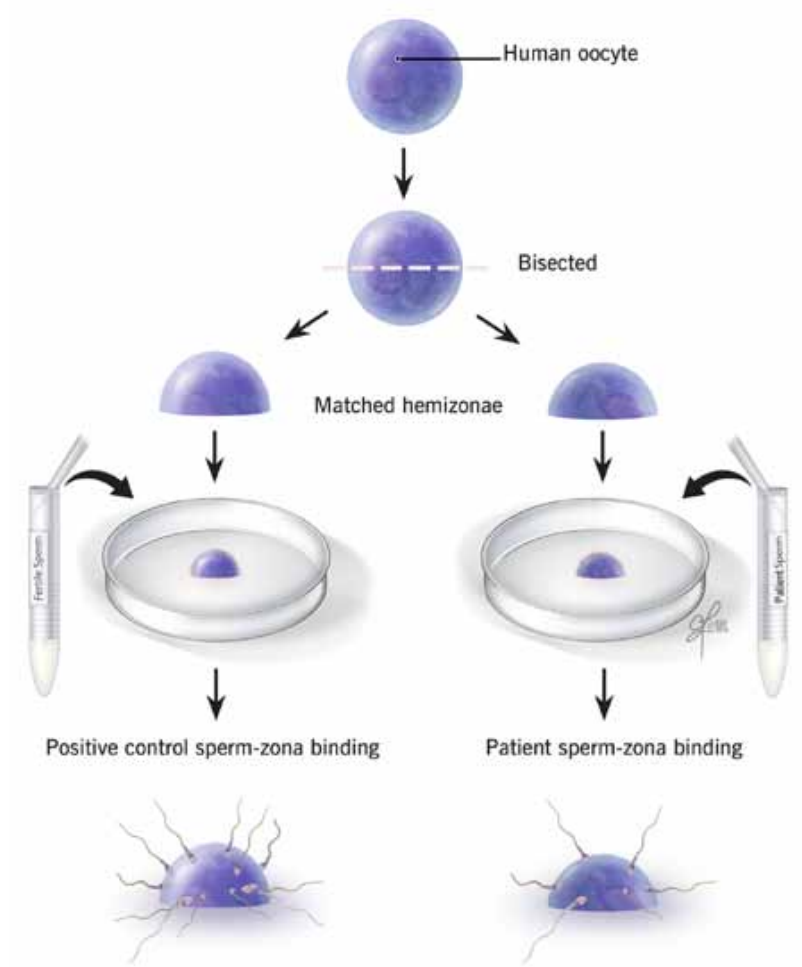

Analysis of sperm hyperactivation motility is also critical to determine fertilization potential. Hyperactivation parameters include curvilinear velocity and lateral head displacement of the sperm. These parameters are difficult to assess manually, both because they are difficult to quantify accurately by observation and also because the heightened movement speed of the sperm which means they often leave the microscope's field of view. In order to accurately evaluate hyperactivation, computer-assisted sperm motility assessment (CAMA) is used which assesses the sperm hyperactivation parameters $(135,136)$. CAMA measurements have been positively correlated with IVF fertilization rates (137); however, it has been shown that assessment of sperm motion 
Figure 4 - (a) Normal physiology: proteolytic enzymes in the acrosome digest through the zona pellucida, allowing for sperm-oolemma fusion. (b) Assessing acrosomal integrity: Different fluorescent lectins are applied to label either the outer membrane or acrosomal contents. (c) Assessing acrosomal enzymatic release: Enzymatic release is induced and the proportion of reacted spermatozoa is assessed. Reprinted from Int J Urol. 2010; 17: 839-47. Samplaski, et al. New generation of diagnostic tests for infertility: review of specialized semen tests, with permission from publisher (John Wiley and Sons) (127).

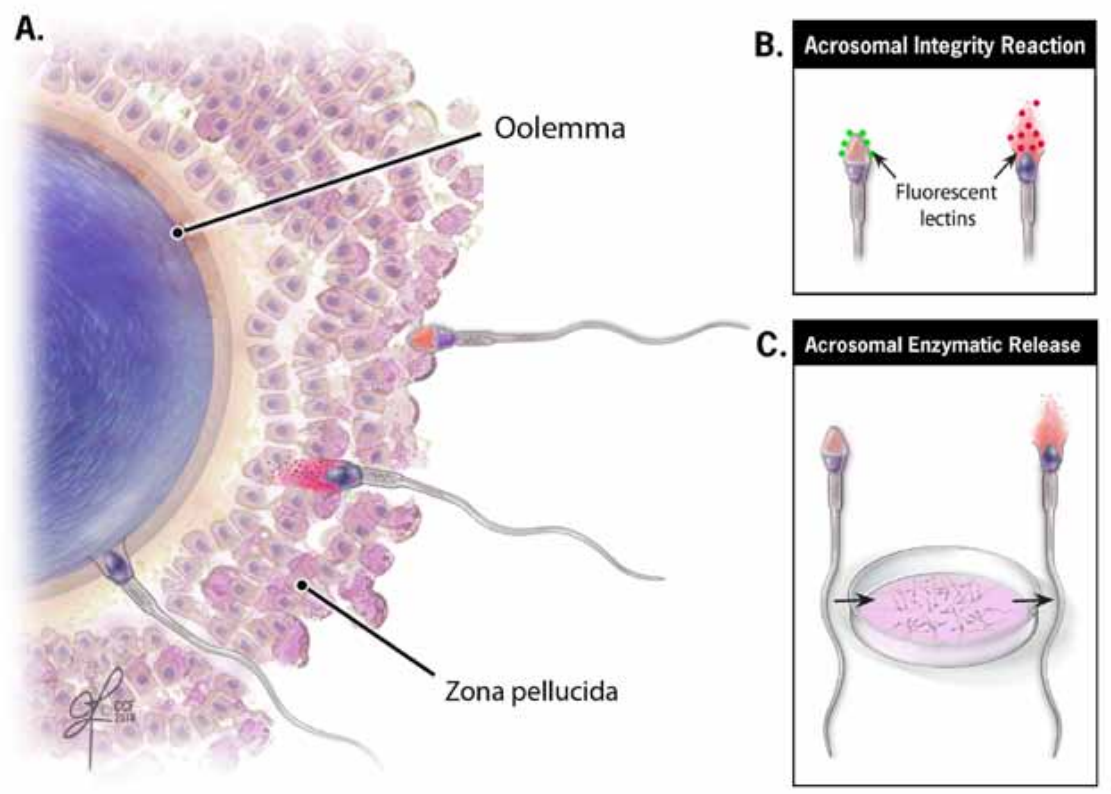

characteristics alone cannot be a reliable predictor of fertilization outcome (138).

Intracytoplasmic sperm injection has emerged as the essential therapeutic modality for sperm fertilization defects. In ICSI, a single spermatozoon is injected directly into the oocyte cytoplasm, bypassing many of the natural steps involved in fertilization such as capacitation, hyperactivation, ZP binding, and AR. Higher rates of pregnancy are obtained by ICSI compared to both standard IVF as well as IUI (139).

Extensive evaluation of male factor infertility in the era of ICSI - An expert opinion

The recent innovation of sophisticated diagnostic testing, achieved in the field of Andrology, has improved our understanding of sperm defects in male infertility. Couples facing unexplained infertility are characterized by being childless despite presence of normal semen parameters and normal female partner evaluation.
Although detailed history taking and physical examination are always crucial to disclose erectile dysfunction or infrequent intercourse, more novel expensive tests are required to scrutinize hidden sperm functional defects. ICSI may help solve the problem of unexplained male infertility and bypass all the natural barriers that a dysfunctional sperm must overcome to induce fertilization. However, such therapy is not without risks and complications. The successful pregnancy achieved by using a dysfunctional sperm carries a risk of transmission of the same infertility traits to the male offspring.

Furthermore, the paternal part of the embryonic genome is actively expressed at the fourto eight-cell stage in human embryos. Therefore, sperm DNA strand breaks that can not be repaired by the oocyte DNA repair system may adversely affect the later stages of embryonic development. Aitken and Krausz recognized that sperm DNA damage is promutagenic and can give rise 
to mutations after fertilization (140). Mutations sustained at the very early stage of embryonic development will be fixed in the germline and may give rise to the induction of infertility, childhood cancer and higher risk of imprinting diseases in the offspring (141). So far, however, short term follow-up studies of children born after ICSI compared with children born after conventional IVF have not been conclusive regarding the risks of congenital malformations, imprinting diseases and health problems in general. Long term studies on the risks and complications of ICSI on the produced offspring are critically required.

Taking this risk into account mandates frequent conduction of sperm function testing to elucidate the basic sperm molecular defects which should be rectified by utilizing molecular targeted therapies before using of the dysfunctional sperm in ICSI. Although these types of therapies are still under investigations, exploring the presence and frequency of metabolic targets may help specifically direct the therapeutic research plans on correcting these metabolic alterations. In addition, identifying certain abnormalities in these tests e.g. sperm DNA integrity defects may help in pre-ICSI counseling of the couples about the advantages as well as the possible failures and complications of ART procedure.

\section{CONCLUSIONS}

Normal semen analysis results, as routinely assessed, do not guarantee fecundity. This premise is important for all clinicians involved in the management of the subfertile men. Currently, one of the chief objectives of male infertility research is to invent a diagnostic test that efficiently correlates with sperm fertilizing potential. Proper understanding of the in vivo process of human fertilization and sperm egg interaction in vitro is the key to envisage the sperm functional alterations with tremendous influence on diagnosis and treatment of male subfertility.

\section{CONFLICT OF INTEREST}

None declared.

\section{REFERENCES}

1. Gnoth C, Godehardt E, Frank-Herrmann P, Friol K, Tigges J, Freundl G: Definition and prevalence of subfertility and infertility. Hum Reprod. 2005; 20: 1144-7.

2. Jarow JP: Diagnostic approach to the infertile male patient. Endocrinol Metab Clin North Am. 2007; 36: 297-311.

3. Hamada A, Esteves SC, Agarwal A: Unexplained male infertility potential causes and management. Human Andrology. 2011; 1: 2-16.

4. Templeton AA, Penney GC: The incidence, characteristics, and prognosis of patients whose infertility is unexplained. Fertil Steril. 1982; 37: 175-82.

5. Collins JA, Crosignani PG: Unexplained infertility: a review of diagnosis, prognosis, treatment efficacy and management. Int J Gynaecol Obstet. 1992; 39: 267-75.

6. Moghissi KS, Wallach EE: Unexplained infertility. Fertil Steril. 1983; 39: 5-21.

7. Esteves SC, Miyaoka R, Agarwal A: An update on the clinical assessment of the infertile male. [corrected]. Clinics (Sao Paulo). 2011; 66: 691-700. Review. Erratum in: Clinics (Sao Paulo). 2012; 67: 203.

8. Agarwal A, Bragais FM, Sabanegh E: Assessing sperm function. Urol Clin North Am. 2008; 35: 157-71.

9. Esteves SC, Zini A, Aziz N, Alvarez JG, Sabanegh ES Jr, Agarwal A: Critical appraisal of World Health Organization's new reference values for human semen characteristics and effect on diagnosis and treatment of subfertile men. Urology. 2012; 79: 16-22.

10. World Health Organization: WHO Laboratory Manual for the Examination and Processing of Human Semen. 5th ed. Geneva: WHO press. 2010.

11. Lewis SE: Is sperm evaluation useful in predicting human fertility? Reproduction. 2007; 134: 31-40.

12. Du Plessis S KA, Agarwal A: The advent of sperm proteomics has arrived. Open Reprod Sci J. 2011; 3: 92-7.

13. Baker MA: The 'omics revolution and our understanding of sperm cell biology. Asian J Androl. 2011; 13: 6-10.

14. Bhasin S: Approach to the infertile man. J Clin Endocrinol Metab. 2007; 92: 1995-2004.

15. Buch JP, Havlovec SK: Variation in sperm penetration assay related to viral illness. Fertil Steril. 1991; 55: 844-6.

16. Potts JM, Sharma R, Pasqualotto F, Nelson D, Hall G, Agarwal $A$ : Association of ureaplasma urealyticum with abnormal reactive oxygen species levels and absence of leukocytospermia. J Urol. 2000; 163: 1775-8.

17. Agarwal A, Prabakaran S, Allamaneni SS: Relationship between oxidative stress, varicocele and infertility: a meta-analysis. Reprod Biomed Online. 2006; 12: 630-3.

18. Polansky FF, Lamb EJ: Do the results of semen analysis predict future fertility? A survival analysis study. Fertil Steril. 1988; 49: 1059-65. 
19. Sigman M, Jarow JP: Endocrine evaluation of infertile men Urology. 1997; 50: 659-64.

20. Mandelbaum SL, Diamond MP, DeCherney AH: The impact of antisperm antibodies on human infertility. J Urol. 1987; 138: 1-8.

21. Anderson DJ, Alexander NJ: Consequences of autoimmunity to sperm antigens in vasectomized men. Clin Obstet Gynaecol. 1979; 6: 425-42.

22. Mazumdar S, Levine AS: Antisperm antibodies: etiology, pathogenesis, diagnosis, and treatment. Fertil Steril. 1998; 70: 799-810.

23. Haas GG Jr, Cines DB, Schreiber AD: Immunologic infertility: identification of patients with antisperm antibody. N Engl J Med. 1980; 303: 722-7.

24. Pattinson HA, Mortimer D: Prevalence of sperm surface antibodies in the male partners of infertile couples as determined by immunobead screening. Fertil Steril. 1987; 48: 466-9.

25. Mandelbaum SL, Diamond MP, DeCherney AH: Relationship of antibodies to sperm head to etiology of infertility in patients undergoing in vitro fertilization/embryo transfer. Am J Reprod Immunol. 1989; 19: 3-5.

26. Moghissi KS, Sacco AG, Borin K: Immunologic infertility. I. Cervical mucus antibodies and postcoital test. Am J Obstet Gynecol. 1980; 136: 941-50.

27. Clarke GN, Lopata A, McBain JC, Baker HW, Johnston WI: Effect of sperm antibodies in males on human in vitro fertilization (IVF). Am J Reprod Immunol Microbiol. 1985; 8: 62-6.

28. Chiu WW, Chamley LW: Clinical associations and mechanisms of action of antisperm antibodies. Fertil Steril. 2004; 82: 529-35.

29. D'Cruz OJ, Haas GG Jr, Wang BL, DeBault LE: Activation of human complement by IgG antisperm antibody and the demonstration of C3 and C5b-9-mediated immune injury to human sperm. J Immunol. 1991; 146: 611-20.

30. D'Cruz OJ, Wang BL, Haas GG Jr.: Phagocytosis of immunoglobulin $\mathrm{G}$ and C3-bound human sperm by human polymorphonuclear leukocytes is not associated with the release of oxidative radicals. Biol Reprod. 1992; 46: 721-32.

31. Taşdemir I, Taşdemir M, Fukuda J, Kodama H, Matsui T, Tanaka T: Sperm immobilization antibodies in infertile male sera decrease the acrosome reaction: a possible mechanism for immunologic infertility. J Assist Reprod Genet. 1996; 13: 413-6.

32. Myogo K, Yamano S, Nakagawa K, Kamada M, Maegawa M, Irahara M, et al.: Sperm-immobilizing antibodies block capacitation in human spermatozoa. Arch Androl. 2001; 47: 135-42.

33. Ayvaliotis B, Bronson R, Rosenfeld D, Cooper G: Conception rates in couples where autoimmunity to sperm is detected. Fertil Steril. 1985; 43: 739-42.

34. Francavilla F, Santucci R, Barbonetti A, Francavilla S: Naturally-occurring antisperm antibodies in men: interference with fertility and clinical implications. An update. Front Biosci. 2007; 12: 2890-911.

35. D'Cruz OJ, Haas GG Jr. Lack of complement activation in the seminal plasma of men with antisperm antibodies associated in vivo on their sperm. Am J Reprod Immunol. 1990; 24: 51-7.

36. Petersen BH, Lammel CJ, Stites DP, Brooks GF: Human seminal plasma inhibition of complement. J Lab Clin Med. 1980; 96: 582-91.

37. Sikka SC: Relative impact of oxidative stress on male reproductive function. Curr Med Chem. 2001; 8: 851-62.

38. Darley-Usmar V, Wiseman $\mathrm{H}$, Halliwell B: itric oxide and oxygen radicals: a question of balance. FEBS Lett. 1995; 369: 131-5.

39. Garrido N, Meseguer M, Simon C, Pellicer A, Remohi J: Prooxidative and anti-oxidative imbalance in human semen and its relation with male fertility. Asian J Androl. 2004; 6: 59-65.

40. Gavella M, Lipovac V: NADH-dependent oxidoreductase (diaphorase) activity and isozyme pattern of sperm in infertile men. Arch Androl. 1992; 28: 135-41.

41. Esteves SC: Effect of cigarette smoking on levels of seminal oxidative stress in infertile men: a prospective study. Int Braz J Urol. 2002;28:484-5.

42. Saleh RA, Agarwal A, Sharma RK, Nelson DR, Thomas AJ Jr.: Effect of cigarette smoking on levels of seminal oxidative stress in infertile men: a prospective study. Fertil Steril. 2002; 78: 491-9.

43. Mahfouz R, Sharma R, Thiyagarajan A, Kale V, Gupta S, Sabanegh $E$, et al.: Semen characteristics and sperm DNA fragmentation in infertile men with low and high levels of seminal reactive oxygen species. Fertil Steril. 2010; 94: 2141-6.

44. Thomas J, Fishel SB, Hall JA, Green S, Newton TA, Thornton SJ: Increased polymorphonuclear granulocytes in seminal plasma in relation to sperm morphology. Hum Reprod. 1997; 12: 2418-21.

45. Plante M, de Lamirande E, Gagnon C: Reactive oxygen species released by activated neutrophils, but not by deficient spermatozoa, are sufficient to affect normal sperm motility. Fertil Steril. 1994; 62: 387-93.

46. Shekarriz M, Sharma RK, Thomas AJ Jr, Agarwal A: Positive myeloperoxidase staining (Endtz test) as an indicator of excessive reactive oxygen species formation in semen. J Assist Reprod Genet. 1995; 12: 70-4.

47. Hamada A, Agarwal A, Sharma R, French DB, Ragheb A, Sabanegh ES Jr.: Empirical treatment of low-level leukocytospermia with doxycycline in male infertility patients. Urology. 2011; 78: 1320-5.

48. Maneesh M, Dutta S, Chakrabarti A, Vasudevan DM: Alcohol abuse-duration dependent decrease in plasma testosterone and antioxidants in males. Indian J Physiol Pharmacol. 2006; 50: 291-6.

49. Griveau JF, Le Lannou D: Reactive oxygen species and human spermatozoa: physiology and pathology. Int J Androl. 1997; 20: 61-9. 
50. Agarwal A, Saleh RA, Bedaiwy MA: Role of reactive oxygen species in the pathophysiology of human reproduction. Fertil Steril. 2003; 79: 829-43.

51. Agarwal A, Said TM: Role of sperm chromatin abnormalities and DNA damage in male infertility. Hum Reprod Update. 2003; 9: 331-45.

52. Shekarriz M, Thomas AJ Jr, Agarwal A: Incidence and level of seminal reactive oxygen species in normal men. Urology. 1995; 45: 103-7.

53. Venkatesh S, Shamsi MB, Deka D, Saxena V, Kumar R, Dada R: Clinical implications of oxidative stress \& sperm DNA damage in normozoospermic infertile men. Indian J Med Res. 2011; 134: 396-8.

54. Agarwal A, Makker K, Sharma R: Clinical relevance of oxidative stress in male factor infertility: an update. Am J Reprod Immunol. 2008; 59: 2-11.

55. Aitken RJ, Harkiss D, Buckingham DW: Analysis of lipid peroxidation mechanisms in human spermatozoa. Mol Reprod Dev. 1993; 35: 302-15.

56. Agarwal A, Allamaneni SS, Said TM: Chemiluminescence technique for measuring reactive oxygen species. Reprod Biomed Online. 2004; 9: 466-8.

57. Weber RF, Dohle GR, Romijn JC: Clinical laboratory evaluation of male subfertility. Adv Clin Chem. 2005; 40: 317-64.

58. Egozcue S, Blanco J, Vendrell JM, García F, Veiga A, Aran $B$, et al.: Human male infertility: chromosome anomalies, meiotic disorders, abnormal spermatozoa and recurrent abortion. Hum Reprod Update. 2000; 6: 93-105.

59. Rives N, Saint Clair A, Mazurier S, Sibert L, Siméon N, Joly G, et al.: Relationship between clinical phenotype, semen parameters and aneuploidy frequency in sperm nuclei of 50 infertile males. Hum Genet. 1999; 105: 266-72.

60. Skaletsky H, Kuroda-Kawaguchi T, Minx PJ, Cordum HS, Hillier L, Brown LG, et al.: The male-specific region of the human $Y$ chromosome is a mosaic of discrete sequence classes. Nature. 2003; 423: 825-37.

61. Hawley RS: The human Y chromosome: rumors of its death have been greatly exaggerated. Cell. 2003; 113: 825-8.

62. Jensen M, Leffers H, Petersen JH, Nyboe Andersen A, Jørgensen $\mathrm{N}$, Carlsen $\mathrm{E}$, et al.: Frequent polymorphism of the mitochondrial DNA polymerase gamma gene (POLG) in patients with normal spermiograms and unexplained subfertility. Hum Reprod. 2004; 19: 65-70.

63. Garrido N, Martínez-Conejero JA, Jauregui J, Horcajadas JA, Simón C, Remohí J, et al.: Microarray analysis in sperm from fertile and infertile men without basic sperm analysis abnormalities reveals a significantly different transcriptome. Fertil Steril. 2009; 91(4 Suppl):1307-10.

64. Oehninger S: Clinical management of male infertility in assisted reproduction: ICSI and beyond. Int J Androl. 2011; 34(5 Pt 2): e319-29.
65. Aitken RJ, De luliis GN, Finnie JM, Hedges A, McLachlan RI: Analysis of the relationships between oxidative stress, DNA damage and sperm vitality in a patient population: development of diagnostic criteria. Hum Reprod. 2010; 25: 2415-26.

66. Shefi S, Turek PJ: Definition and current evaluation of subfertile men. Int Braz J Urol. 2006; 32: 385-97.

67. Evenson DP, Jost LK, Marshall D, Zinaman MJ, Clegg E, Purvis $\mathrm{K}$, et al.: Utility of the sperm chromatin structure assay as a diagnostic and prognostic tool in the human fertility clinic. Hum Reprod. 1999; 14: 1039-49.

68. Zini A, Bielecki R, Phang D, Zenzes MT: Correlations between two markers of sperm DNA integrity, DNA denaturation and DNA fragmentation, in fertile and infertile men. Fertil Steril. 2001; 75: 674-7.

69. Aitken RJ, Irvine DS, Wu FC: Prospective analysis of spermoocyte fusion and reactive oxygen species generation as criteria for the diagnosis of infertility. Am J Obstet Gynecol. 1991; 164: 542-51.

70. Evenson DP, Wixon R: Data analysis of two in vivo fertility studies using Sperm Chromatin Structure Assay-derived DNA fragmentation index vs. pregnancy outcome. Fertil Steril. 2008; 90: 1229-31.

71. Loft S, Kold-Jensen T, Hjollund NH, Giwercman A, Gyllemborg $\mathrm{J}$, Ernst $\mathrm{E}$, et al:: Oxidative DNA damage in human sperm influences time to pregnancy. Hum Reprod. 2003; 18: 1265-72.

72. Bungum M, Humaidan $\mathrm{P}$, Axmon A, Spano M, Bungum L, Erenpreiss $\mathrm{J}$, et al.: Sperm DNA integrity assessment in prediction of assisted reproduction technology outcome. Hum Reprod. 2007; 22: 174-9.

73. Borini A, Tarozzi N, Bizzaro D, Bonu MA, Fava L, Flamigni $C$, et al.: Sperm DNA fragmentation: paternal effect on early post-implantation embryo development in ART. Hum Reprod. 2006; 21: 2876-81.

74. Benchaib M, Lornage J, Mazoyer C, Lejeune H, Salle B, François Guerin $\mathrm{J}$ : Sperm deoxyribonucleic acid fragmentation as a prognostic indicator of assisted reproductive technology outcome. Fertil Steril. 2007; 87: 93-100.

75. Check JH, Graziano V, Cohen R, Krotec J, Check ML: Effect of an abnormal sperm chromatin structural assay (SCSA) on pregnancy outcome following (IVF) with ICSI in previous IVF failures. Arch Androl. 2005; 51: 121-4.

76. Esteves SC, Sharma RK, Thomas AJ Jr, Agarwal A: Effect of swim-up sperm washing and subsequent capacitation on acrosome status and functional membrane integrity of normal sperm. Int J Fertil Womens Med. 2000; 45: 335-41.

77. Hortas ML, Castilla JA, Gil MT, Samaniego F, Morell M, Redondo M: Alterations in sperm protein phosphorylation in male infertility. Andrologia. 2001; 33: 282-6.

78. Visconti PE, Galantino-Homer H, Moore GD, Bailey JL, Ning X, Fornes $\mathrm{M}$, et al.: The molecular basis of sperm capacitation. $\mathrm{J}$ Androl. 1998; 19: 242-8. 
79. White DR, Aitken RJ: Relationship between calcium, cyclic AMP, ATP, and intracellular $\mathrm{pH}$ and the capacity of hamster spermatozoa to express hyperactivated motility. Gamete Res. 1989; 22: 163-77.

80. Sukcharoen N, Keith J, Irvine DS, Aitken RJ: Definition of the optimal criteria for identifying hyperactivated human spermatozoa at $25 \mathrm{~Hz}$ using in-vitro fertilization as a functional end-point. Hum Reprod. 1995; 10: 2928-37.

81. Aitken RJ: Sperm function tests and fertility. Int J Androl. 2006; 29: 69-75; discussion 105-8.

82. Mackenna A: Contribution of the male factor to unexplained infertility: a review. Int J Androl. 1995; 18(Suppl 1): 58-61.

83. Lishko PV, Kirichok Y: The role of Hv1 and CatSper channels in sperm activation. J Physiol. 2010; 588: 4667-72.

84. Suarez SS: Control of hyperactivation in sperm. Hum Reprod Update. 2008; 14: 647-57.

85. Carlson AE, Burnett LA, del Camino D, Quill TA, Hille B, Chong JA, et al:: Pharmacological targeting of native CatSper channels reveals a required role in maintenance of sperm hyperactivation. PLoS One. 2009; 4: e6844.

86. Avenarius MR, Hildebrand MS, Zhang Y, Meyer NC, Smith LL, Kahrizi K, et al.: Human male infertility caused by mutations in the CATSPER 1 channel protein. Am J Hum Genet. 2009; 84: 505-10.

87. Hildebrand MS AM, Smith RJH. CATSPER-Related Male Infertility. Seattle: University of Washington Seattle (WA); 1993-2009 Dec 03. [cited 2012 January 2]; Available from: http://0-www.ncbi.nlm.nih.gov.library.ccf.org/ pubmed/20301780.

88. Nixon B, Lu Q, Wassler MJ, Foote CI, Ensslin MA, Shur BD: Galactosyltransferase function during mammalian fertilization. Cells Tissues Organs. 2001; 168: 46-57.

89. Miller DJ, Macek MB, Shur BD: Complementarity between sperm surface beta-1,4-galactosyltransferase and egg-coat ZP3 mediates sperm-egg binding. Nature. 1992; 357: 589-93.

90. Cherr GN, Yudin Al, Overstreet JW: The dual functions of GPI-anchored PH-20: hyaluronidase and intracellular signaling. Matrix Biol. 2001; 20: 515-25.

91. Liu DY, Garrett C, Baker HW: Clinical application of spermoocyte interaction tests in in vitro fertilization--embryo transfer and intracytoplasmic sperm injection programs. Fertil Steril. 2004; 82: 1251-63.

92. Liu de Y, Liu ML, Garrett C, Baker HW: Comparison of the frequency of defective sperm-zona pellucida (ZP) binding and the ZP-induced acrosome reaction between subfertile men with normal and abnormal semen. Hum Reprod. 2007; 22: $1878-84$.

93. Liu DY, Clarke GN, Lopata A, Johnston WI, Baker HW: A sperm-zona pellucida binding test and in vitro fertilization. Fertil Steril. 1989; 52: 281-7.
94. Florman HM, Tombes RM, First NL, Babcock DF: An adhesion-associated agonist from the zona pellucida activates $\mathrm{G}$ protein-promoted elevations of internal $\mathrm{Ca} 2+$ and $\mathrm{pH}$ that mediate mammalian sperm acrosomal exocytosis. Dev Biol. 1989; 135: 133-46.

95. Baldi E, Casano R, Falsetti C, Krausz C, Maggi M, Forti G: Intracellular calcium accumulation and responsiveness to progesterone in capacitating human spermatozoa. J Androl. 1991; 12: 323-30.

96. Osman RA, Andria ML, Jones AD, Meizel S: Steroid induced exocytosis: the human sperm acrosome reaction. Biochem Biophys Res Commun. 1989; 160: 828-33.

97. Liu DY, Clarke GN, Martic M, Garrett C, Baker HW: Frequency of disordered zona pellucida (ZP)-induced acrosome reaction in infertile men with normal semen analysis and normal spermatozoa-ZP binding. Hum Reprod. 2001; 16: 1185-90.

98. Juul S, Karmaus W, Olsen J: Regional differences in waiting time to pregnancy: pregnancy-based surveys from Denmark, France, Germany, Italy and Sweden. The European Infertility and Subfecundity Study Group. Hum Reprod. 1999; 14: $1250-4$.

99. Jensen TK, Slama R, Ducot B, Suominen J, Cawood EH, Andersen $A G$, et al.: Regional differences in waiting time to pregnancy among fertile couples from four European cities. Hum Reprod. 2001; 16: 2697-704.

100. Hull MG, Glazener CM, Kelly NJ, Conway DI, Foster PA, Hinton RA, et al.: Population study of causes, treatment, and outcome of infertility. Br Med J (Clin Res Ed). 1985; 291: 1693-7.

101. van der Steeg JW, Steures P, Hompes PG, Eijkemans MJ, van der Veen F, Mol BW: Investigation of the infertile couple: a basic fertility work-up performed within 12 months of trying to conceive generates costs and complications for no particular benefit. Hum Reprod. 2005; 20: 2672-4.

102. Snick HK, Snick TS, Evers JL, Collins JA: The spontaneous pregnancy prognosis in untreated subfertile couples: the Walcheren primary care study. Hum Reprod. 1997; 12: 1582-8.

103. Aboulghar MA, Mansour RT, Serour GI, Al-Inany HG: Diagnosis and management of unexplained infertility: an update. Arch Gynecol Obstet. 2003; 267: 177-88.

104. Brandes M, Hamilton CJ, van der Steen JO, de Bruin JP, Bots RS, Nelen WL, et al.: Unexplained infertility: overall ongoing pregnancy rate and mode of conception. Hum Reprod. 2011; 26: 360-8.

105. Glazener CM, Ford WC, Hull MG: The prognostic power of the post-coital test for natural conception depends on duration of infertility. Hum Reprod. 2000; 15: 1953-7.

106. Male Infertility Best Practice Policy Committee of the American Urological Association; Practice Committee of the American Society for Reproductive Medicine: Report on optimal evaluation of the infertile male. Fertil Steril. 2006; 86(5 Suppl 1): S202-9. 
107. Devroey P, Fauser BC, Diedrich K; Evian Annual Reproduction (EVAR) Workshop Group 2008: Approaches to improve the diagnosis and management of infertility. Hum Reprod Update. 2009; 15: 391-408.

108. WHO laboratory manual for the examination and processing of human semen. Geneva: World Health Organization; 2010.

109. Räsänen M, Saarikoski S, Penttilä I, Agrawal YP: A flow cytometric study on the effect of low dose cyclic prednisolone treatment on sperm-bound antibody levels. Hum Reprod. 1994; 9: 889-93.

110. Haas GG Jr, Manganiello P: A double-blind, placebo-controlled study of the use of methylprednisolone in infertile men with sperm-associated immunoglobulins. Fertil Steril. 1987; 47: 295-301.

111. Agarwal A: Treatment of immunological infertility by sperm washing and intrauterine insemination. Arch Androl. 1992; 29: 207-13.

112. Kutteh WH, Kilian M, Ermel LD, Mestecky J: Antisperm antibodies in infertile women: subclass distribution of immunoglobulin ( $\mathrm{Ig}$ ) A antibodies and removal of IgA sperm-bound antibodies with a specific IgA1 protease. Fertil Steril. 1995; 63: 63-70.

113. Lähteenmäki A, Reima I, Hovatta 0: Treatment of severe male immunological infertility by intracytoplasmic sperm injection. Hum Reprod. 1995; 10: 2824-8.

114. Esteves SC, Schneider DT, Verza S Jr.: Influence of antisperm antibodies in the semen on intracytoplasmic sperm injection outcome. Int Braz J Urol. 2007; 33: 795-802.

115. Cocuzza M, Agarwal A: Nonsurgical treatment of male infertility: specific and empiric therapy. Biologics. 2007; 1: 259-69.

116. Showell MG, Brown J, Yazdani A, Stankiewicz MT, Hart RJ: Antioxidants for male subfertility. Cochrane Database Syst Rev. 2011; 19: CD007411.

117. Fraser L: Structural damage to nuclear DNA in mammalian spermatozoa: its evaluation techniques and relationship with male infertility. Pol J Vet Sci. 2004; 7: 311-21.

118. Shamsi MB, Kumar R, Dada R: Evaluation of nuclear DNA damage in human spermatozoa in men opting for assisted reproduction. Indian J Med Res. 2008; 127: 115-23.

119. Chohan KR, Griffin JT, Lafromboise M, De Jonge CJ, Carrell DT: Comparison of chromatin assays for DNA fragmentation evaluation in human sperm. J Androl. 2006; 27: 53-9.

120. Erenpreiss J, Hlevicka S, Zalkalns J, Erenpreisa J: Effect of leukocytospermia on sperm DNA integrity: a negative effect in abnormal semen samples. J Androl. 2002; 23: 717-23.

121. Evenson DP, Larson KL, Jost LK: Sperm chromatin structure assay: its clinical use for detecting sperm DNA fragmentation in male infertility and comparisons with other techniques. J Androl. 2002; 23: 25-43.
122. Duran EH, Morshedi M, Taylor S, Oehninger S: Sperm DNA quality predicts intrauterine insemination outcome: a prospective cohort study. Hum Reprod. 2002; 17: 3122-8.

123. Sharma RK, Sabanegh E, Mahfouz R, Gupta S, Thiyagarajan A, Agarwal A: TUNEL as a test for sperm DNA damage in the evaluation of male infertility. Urology. 2010; 76: 1380-6.

124. Greco E, Scarselli F, lacobelli M, Rienzi L, Ubaldi F, Ferrero S, et al.: Efficient treatment of infertility due to sperm DNA damage by ICSI with testicular spermatozoa. Hum Reprod. 2005; 20: 226-30.

125. Steele EK, McClure N, Maxwell RJ, Lewis SE: A comparison of DNA damage in testicular and proximal epididymal spermatozoa in obstructive azoospermia. Mol Hum Reprod. 1999; 5: 831-5.

126. Zini A, Meriano J, Kader K, Jarvi K, Laskin CA, Cadesky K: Potential adverse effect of sperm DNA damage on embryo quality after ICSI. Hum Reprod. 2005; 20: 3476-80.

127. Samplaski MK, Agarwal A, Sharma R, Sabanegh E: New generation of diagnostic tests for infertility: review of specialized semen tests. Int J Urol. 2010; 17: 839-47. Erratum in: Int J Urol. 2011; 18: 262.

128. Aitken RJ, Best FS, Richardson DW, Djahanbakhch 0, Mortimer D, Templeton AA, et al.: An analysis of sperm function in cases of unexplained infertility: conventional criteria, movement characteristics, and fertilizing capacity. Fertil Steril. 1982; 38: 212-21.

129. Freeman MR, Archibong AE, Mrotek JJ, Whitworth CM, Weitzman GA, Hill GA: Male partner screening before in vitro fertilization: preselecting patients who require intracytoplasmic sperm injection with the sperm penetration assay. Fertil Steril. 2001; 76: 1113-8.

130. Soffer Y, Golan A, Herman A, Pansky M, Caspi E, Ron-El R: Prediction of in vitro fertilization outcome by sperm penetration assay with TEST-yolk buffer preincubation. Fertil Steril. 1992; 58: 556-62.

131. Liu DY, Lopata A, Johnston WI, Baker HW: A human sperm-zona pellucida binding test using oocytes that failed to fertilize in vitro. Fertil Steril. 1988; 50: 782-8.

132. Sigman M, Baazeem A, Zini A: Semen analysis and sperm function assays: what do they mean? Semin Reprod Med. 2009; 27: 115-23. Erratum in: Semin Reprod Med. 2009; 27: 294. Baazeem, Abdulaziz [added].

133. Esteves SC, Sharma RK, Thomas AJ Jr, Agarwal A: Evaluation of acrosomal status and sperm viability in fresh and cryopreserved specimens by the use of fluorescent peanut agglutinin lectin in conjunction with hypo-osmotic swelling test. Int Braz J Urol. 2007; 33: 364-74; discussion 375-6.

134. Liu DY, Baker HW: Frequency of defective sperm-zona pellucida interaction in severely teratozoospermic infertile men. Hum Reprod. 2003; 18: 802-7.

135. Paston MJ, Sarkar S, Oates RP, Badawy SZ: Computer-aided semen analysis variables as predictors of male fertility potential. Arch Androl. 1994; 33: 93-9. 
136. Esteves SC, Sharma RK, Thomas AJ Jr, Agarwal A: Improvement in motion characteristics and acrosome status in cryopreserved human spermatozoa by swim-up processing before freezing. Hum Reprod. 2000; 15: 2173-9.

137. Cooper T: Physiology of Sperm Maturation and Fertilization. In: Nieschlag E BH, (ed.), Andrology: Male Reproductive Health and Dysfunction. 3rd ed. Verlag Berlin Heidelberg: Springer; 2010; p. 61-86.
138. Macleod IC, Irvine DS: The predictive value of computerassisted semen analysis in the context of a donor insemination programme. Hum Reprod. 1995; 10: 580-6.

139. Liu DY, Baker HW: Evaluation and assessment of semen for IVF/ICSI. Asian J Androl. 2002; 4: 281-5.

140. Aitken RJ, Krausz C: Oxidative stress, DNA damage and the Y chromosome. Reproduction. 2001; 122: 497-506.

141. Alukal JP, Lamb DJ: Intracytoplasmic sperm injection (ICSI)--what are the risks? Urol Clin North Am. 2008; 35: 277-88.

Correspondence address:

Dr. Ashok Agarwal Professor, Lerner College of Medicine Director, Center for Reproductive Medicine

Director, Andrology Laboratory Cleveland Clinic, Desk A19.1 9500 Euclid Avenue Cleveland, Ohio 44195, United States

FAX: + 1216 445-6049

E-mail: agarwaa@ccf.org 